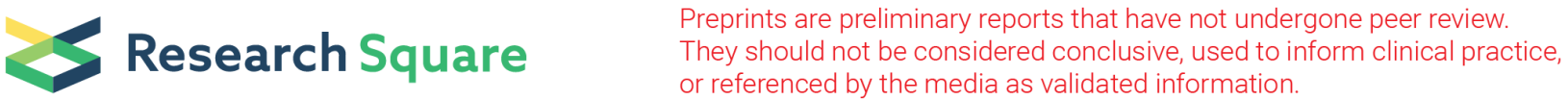 \\ Study On The Steel-Aluminum Plastic Clinching of The Inclined Wall Die
}

\section{Menghan Wang ( $\nabla$ cquwmh@163.com)}

College of Materials Science and Engineering of Chongqing University

\section{Yifeng Chen}

College of Materials Science and Engineering of Chongqing University

\section{Yan Han}

College of Materials Science and Engineering of Chongqing University

Lei Li

College of Materials Science and Engineering of Chongqing University

\section{Menglong Du}

College of Materials Science and Engineering of Chongqing University

\section{Research Article}

Keywords: Plastic clinching, Heterogeneous sheets, Inclined wall die, Finite element method, Failure

Posted Date: December 3rd, 2021

DOI: https://doi.org/10.21203/rs.3.rs-1127614/v1

License: (c) (1) This work is licensed under a Creative Commons Attribution 4.0 International License. Read Full License 


\title{
Study on the steel-aluminum plastic clinching of the inclined wall die
}

\author{
Menghan Wang ${ }^{1} \cdot$ Yifeng Chen $^{1} \cdot$ Yan Han $^{1} \cdot$ Lei Li $^{1} \cdot$ Menglong Du $^{1}$
}

\begin{abstract}
Aiming at the problems of low strength and unsatisfactory connection quality of plastic clinching of heterogeneous lightweight materials for the cars body, the Q235 steel sheets, and 5052 aluminum alloy sheets were taken as the research objects, and the inclined wall die for plastic clinching was designed based on the deformation and flow characteristics of sheets in the plastic clinching process. The elastic-plastic finite element numerical simulation and experimental research were used to analyze the plastic clinching process of the inclined wall die, and the failure mode and mechanism of the clinching joints in the shear and peel experiment were deeply studied. The results show that the inclined wall die can effectively increase the interlock value of the joints and reduce the maximum joining force during the clinching process under the condition of ensuring the neck thickness of the joints. When the inclined wall angle $\boldsymbol{\alpha}$ increases from $90^{\circ}$ to $100^{\circ}$, the interlock value increases by $38.9 \%$, and the maximum joining force decreases by $8.3 \%$. The influence of inclined wall structure on joint quality can be divided into extrusion stage, radial inflow stage, and stability stage. The comparison between the clinching experiment and the finite element results shows that the two results are in good agreement, which proves that the finite element model of plastic clinching of inclined wall die has a high degree of credibility, and verifies the feasibility of practical application of inclined wall die. Finally, under shear and peel loads, the main failure mode of the joints is separation failure.
\end{abstract}

Keywords Plastic clinching $\cdot$ Heterogeneous sheets $\cdot$ Inclined wall die $\cdot$ Finite element method $\cdot$ Failure

\section{Introduction}

With the development of the automobile industry and the strong requirements of energy conservation and emission reduction, higher requirements are put forward for automobile lightweight [1-4]. Clinching, as a kind of sheet mechanical connection process, has the characteristics of a simple process, high flexibility, economic and environmental protection, and a high degree of automation. Its process principle is to form an interlock between sheets by using the plastic deformation of sheets to realize the connection of sheets. Compared with riveting, due to the lack of rivets, clinching has prominent advantages in a lightweight design. It has become an important design method for the lightweight design of products in automotive, aerospace, and other fields, and has also become a hot spot in the research and application of connection technology. A large number of scholars have done a lot of work on the riveting strength and riveting of heterogeneous materials. Lambiase et al. $[5,6]$ designed an extensible die for clinching and found that the peel strength of the joints obtained by

Menghan Wang

cquwmh@163.com

1 School of Materials Science and Engineering, Chongqing University, Chongqing 400030, China using the extensible die increased by about $40 \%$. In addition, the extensible die was also used to increase the re-forming process based on the pre-punched clinching of carbon fiber sheets, to realize the clinching between aluminum alloy sheets and carbon fiber sheets. Chao et al. $[7,8]$ proposed a clinching and reshaping process, which used a flat die for compressing and reshaping of the joints, improved the strength of clinching joining, and solved the problem of protrusion in the appearance of the joints. In addition, they developed a new technology of flat-rivet clinching process (FRCP) [9] and explored the influence of friction coefficient and specimen material on material flow. The results showed that the friction coefficient of other contact surfaces except for the contact region between the upper sheet and blank holder played an important role during the material flow, and the higher the sheet strength and material flow resistance, the greater the riveting force required by FRCP. Lee $[10,11]$ applied the pre-opening clinching to the connection between aluminum alloy and other sheets with poor plasticity, established the finite element model, and verified the feasibility of the process from both simulation and experiment. Lin et al. [12] Used the preheating riveting process to connect aluminum alloy and carbon fiber reinforced thermoplastic composites and analyzed the process through the quasi-static tensile test, optical micrograph, and fatigue test. It is found that heating can improve the ductility of the sheets, and the interlock of joints could also increase when the riveting force increases and the die geometry 
had an important influence on the joints. In addition, two failure modes, button separation, and neck fracture were found in the failed clinch joints under low-cycle and high-cycle conditions. He et al. [13] Used the finite element method to simulate the riveting process of the extensible die and designed experiments to verify it, explored the deformation and failure of the extensible die clinching joints under monotonic tensile loading, and finally used the normal hypothesis tests to examine the rationality of the test data. They found the experimental results were in good agreement with the predictions. Zhang and Stephan et al. [14,15] combined the pre-punching process with clinching and completed the punching of the lower sheet in the clinching process through the designed die. Thereby realizing the clinching of aluminum alloy sheets with high-strength and ultra-high-strength steel sheets.

Due to the great difference in hardness, strength, and plastic deformation of steel and aluminum sheets, the flow behavior of materials is very different during clinching. There are certain difficulties in the connection of steel-aluminum heterogeneous plates with traditional clinching, and its connection strength can not meet the requirements of use. Therefore, Eshtayeh et al. [16] explored the influence of various die parameters on the clinching of steel-aluminum dissimilar materials based on LS-DYNA software. They found that the optimal geometrical parameters of the die groove height, die diameter, punch diameter, punch corner radius and the gap between punch and blank holder had the greatest influence on the bottom and neck thicknesses. In addition, when the thickness of the bottom or neck thickness increased, the interlock decreased. The inclined wall die structure appeared in the finite element model. Lambiase et al. [5] formed clinching joints with different forming forces with fixed dies and extensible dies and tested the joints by shear and peel tests. It was found that the joints obtained by extensible dies had greater interlock and higher strength, and some joints had an obvious inclined wall effect. Although the existing research work improved the strength of clinching from the method of die optimization and the combination of various processes and has achieved some results. The straight-wall die is mostly used in die optimization, and there are little researches on clinching by inclined wall die. Therefore, there is still a lack of theoretical research on clinching based on inclined wall die.

In this study, according to the flow characteristics of sheets in the process of plastic clinching, the structure of the inclined wall die of plastic clinching was improved. Combined with elastic-plastic finite element numerical simulation and experiment, the clinching process with different inclined wall angles was explored, and the mechanism of the inclined wall die was deeply analyzed.

\section{Finite element analysis}

To better realize the plastic connection of steel-aluminum heterogeneous sheets, the general finite element software ABAQUS was selected to simulate the plastic clinching process. Clinching joints were circular joints, which had better mechanical properties and stability than square joints $[17,18]$. The geometric and mechanical boundary conditions of circular joints were approximately axisymmetric, so the model could be simplified into the two-dimensional axisymmetric model. At present, most of the new lightweight cars use 5000, 6000 series, and some 7000 series aluminum alloys. The main alloying element of 5000 series aluminum alloy is magnesium, which has good forming properties. Therefore, a 5052 aluminum alloy sheet was used in this study, and the thickness of the aluminum alloy sheets of the car's body was generally $1.5 \mathrm{~mm}[19,20]$. For steel, Q235 steel sheet, which was widely used on the body of the car, the thickness of steel sheets was set as $1 \mathrm{~mm}$ [21]. In the finite element model, the upper sheet was $1.5 \mathrm{~mm} 5052$ aluminum alloy sheet and the lower sheet was $1 \mathrm{~mm}$ Q235 steel sheet. Their basic mechanical properties are shown in Table 1 [22-24].

Table 1 The basic mechanical properties of AA5052 and Q235 alloy sheets

\begin{tabular}{ccccc}
\hline Material & $\begin{array}{c}\text { Young's } \\
\text { modulus } \\
(\mathrm{GPa})\end{array}$ & $\begin{array}{c}\text { Poisson's } \\
\text { ratio }\end{array}$ & $\begin{array}{c}\text { Yield } \\
\text { strength } \\
(\mathrm{MPa})\end{array}$ & $\begin{array}{c}\text { Tensile } \\
\text { strength } \\
(\mathrm{MPa})\end{array}$ \\
\hline AA5052 & 70 & 0.34 & 185.26 & 193 \\
Q235 & 210 & 0.3 & 235 & 580 \\
\hline
\end{tabular}

The quality of the clinching joints depends on the flow of the sheet metal. To improve the fluidity of the sheet metal during the clinching process and the connection quality, an inclined wall die structure was designed based on the material flow characteristics of the traditional clinching. By optimizing the clinching through the inclined wall structure, the inclined wall dies structure can improve the plastic deformation flow of the upper and lower sheets, so that materials flow to the die groove and surrounding of the die, thereby increasing the interlock value of the clinching joints. The steel-aluminum plastic clinching joints of the inclined wall die are shown in Fig. 1. During the clinching process, the plastic deformation of the sheet followed the law of minimum resistance. Under the extrusion action of punch and die, the use of an inclined wall structure will make the lower sheet close to the inclined wall of the die. Then the sheet metal will easier to flow to the groove and surroundings of the die under the guidance of an inclined wall, to increase the interlock value of clinching joints. Besides, after the tendency of the lower sheet flow to the groove and surrounding of the die increases, the extrusion force 
and deformation required for the upper sheet to squeeze the lower sheet can also be reduced, to alleviate the thinning of the upper sheet and ensure the neck thickness of the clinching joints. The joining force-displacement curves of the simulation results of steel-aluminum plastic clinching of the inclined wall die with different inclined wall angles are shown in Fig. 2. With the increase of inclined wall angle, the maximum joining force required for steel-aluminum clinching decreases gradually. When the inclined wall angle $\boldsymbol{\alpha}$ increases from $90^{\circ}$ to $100^{\circ}$, the maximum joining force decreases by about $8.3 \%$. Therefore, the inclined wall structure of the die could not only effectively increase the interlock value of the steel-aluminum clinching joints, but reduce the maximum joining force during the clinching process.

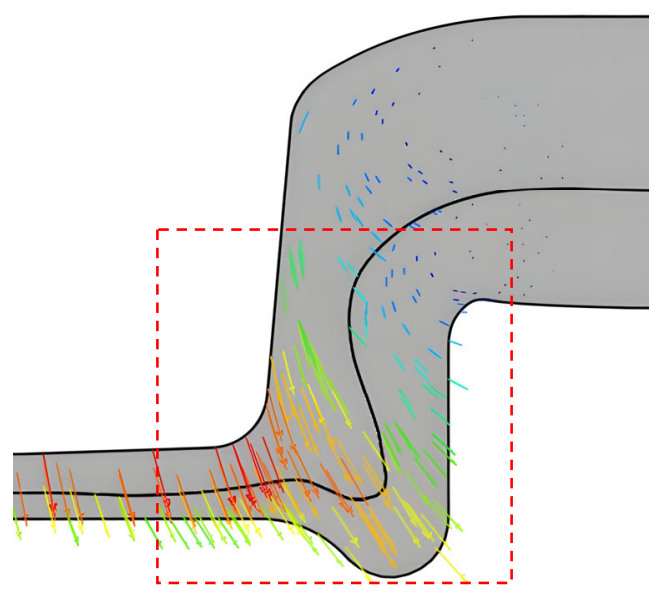

(a)

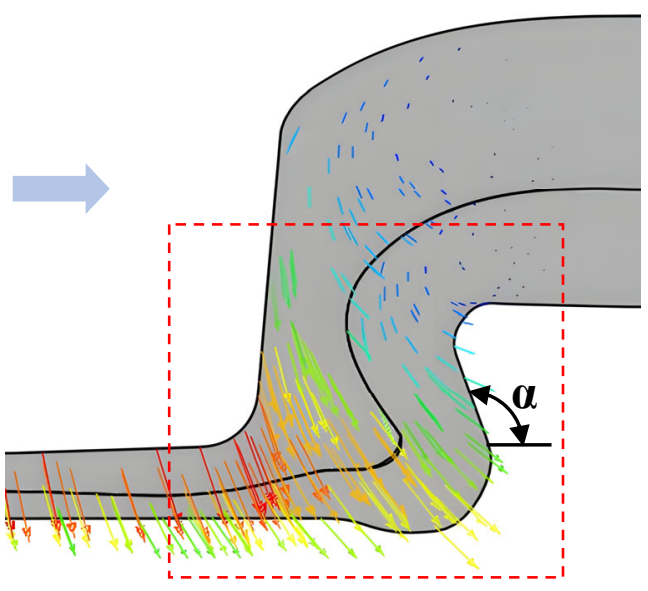

(b)

Fig. 1 Steel-aluminum plastic clinching joints of the inclined wall die. (a) Clinching joints of traditional die, (b) Clinching joints of inclined wall die.

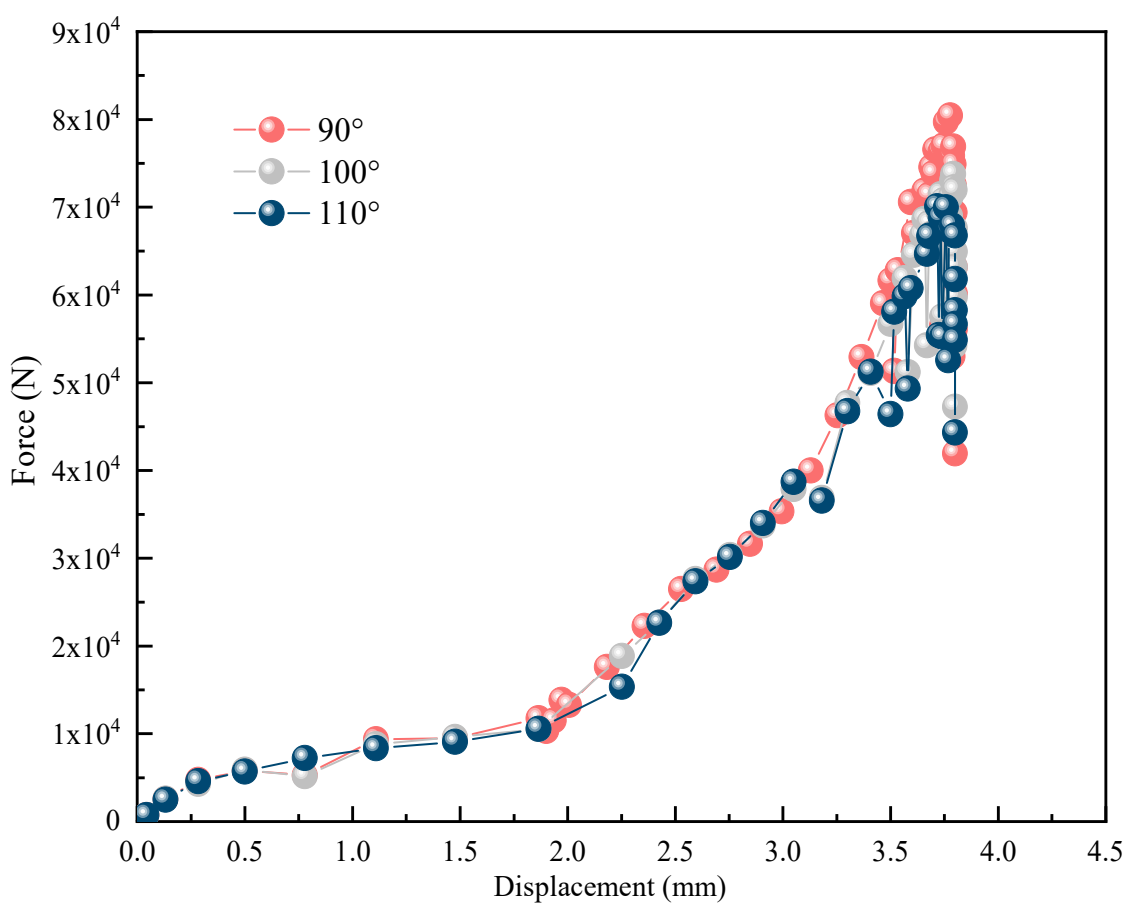

Fig. 2 The joining force-displacement curves of the simulation results of steel-aluminum plastic clinching of the inclined wall die with different inclined wall angles

\section{Experiment}

\subsection{Experimental equipment and mold design}

During the experiment, the main equipment was
WDW-100 material forming performance testing machine. The main feature of the inclined wall die is the inclined wall structure of the female dies inclined to the inside. The inclined wall structure can increase the interlock of the clinching joints while ensuring neck thickness. However, if the integral die structure is adopted, the joints are not easy to be taken out from the 
female die after clinching, and it is extremely easy to cause damage to the joints or die. Therefore, the petal dies structure needs to be adopted. To facilitate processing, the inclined wall die was designed into a two petal structure, and the inclined wall angle $\boldsymbol{\alpha}$ was set as $100^{\circ}$. For the punch, to facilitate the control of the movement of the punch in the clinching process, the corresponding guiding structure was designed. The final designed inclined wall die assembly for plastic clinching is shown in Fig. 3 (a), and the actual processed whole die is shown in Figure 3 (b).

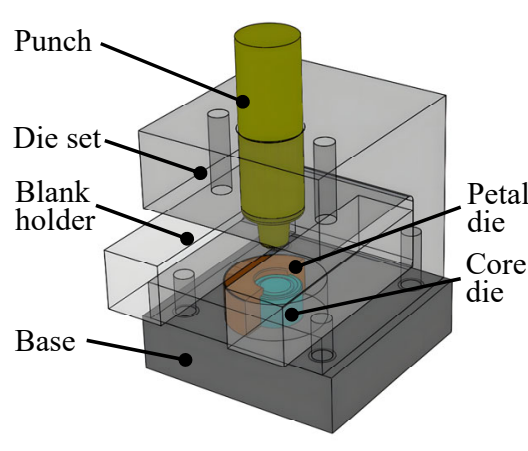

(a)

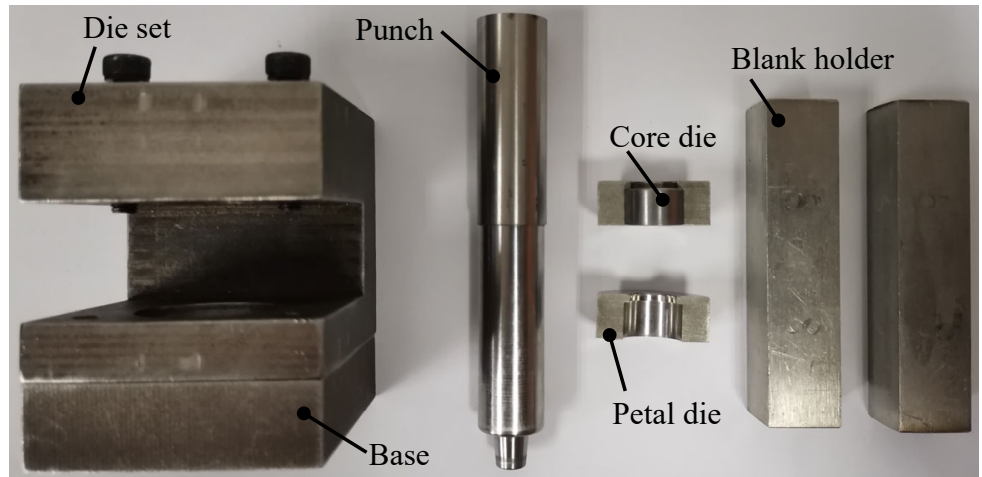

(b)

Fig. 3 Inclined wall die for plastic clinching joints. (a) Inclined wall dies assembly drawing, (b) Actual processed whole die.

\subsection{Clinching scheme}

To verify the effect of inclined wall die, except the appearance of the clinching joints, the neck thickness and interlock value of the joints also need to be measured. Therefore, the joint cutting sample needs to be prepared. According to the actual use of the clinching joints, shear and peel strength are commonly used to measure the mechanical properties of the joints; Therefore, shear and peel experiments are used to evaluate the joint's quality. During the experiment, the upper sheet still adopted $1.5 \mathrm{~mm} 5052$ aluminum alloy sheet, and the lower sheet adopted $1 \mathrm{~mm}$ Q235 steel sheet. The dimensions of cut and sheared samples are shown in Fig. 4 (a), and the dimensions of the peeled sample are shown in Fig. 4 (b). Before clinching, set the clinching speed as $1 \mathrm{~mm} / \mathrm{s}$ and the pressing amount of punch as $3.8 \mathrm{~mm}$. After clinching, returned the press, removed the die, took out the clinching samples. Finally, three sets of cut samples and three sets of sheared and peeled samples were completed.

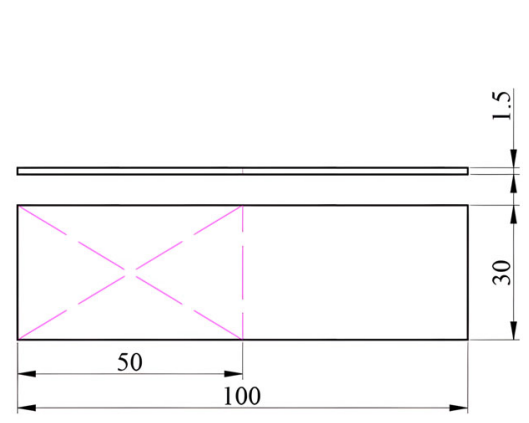

(a)

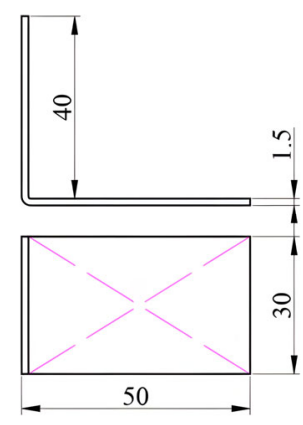

(b)
Fig. 4 Clinching sample. (a) Cut and shear samples, (b) Peel sample.

\subsection{Shear and peel experiments of clinching joints}

To further test the mechanical properties of the clinching joints obtained by inclined wall die and study the failure process and mechanism of the clinching joints, it is necessary to carry out shear and peel experiments on the joints. As shown in Fig. 5, clamped the prepared sample on the tensile clamp of the testing machine, and the clamped length of both ends of the sample is $20 \mathrm{~mm}$. During the experiment, the tensile speed was controlled to $1 \mathrm{~mm} / \mathrm{min}$, and multiple groups of tests were carried out on the joints under two working conditions. The main failure modes of plastic clinching joints of steel-aluminum heterogeneous sheets were obtained, and the corresponding displacement-load curve was output.

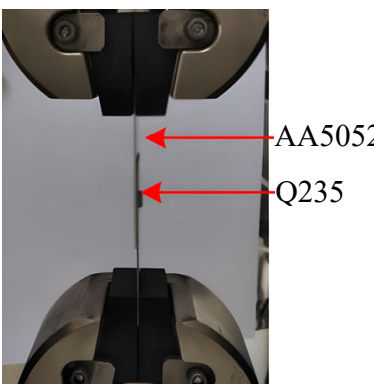

(a)

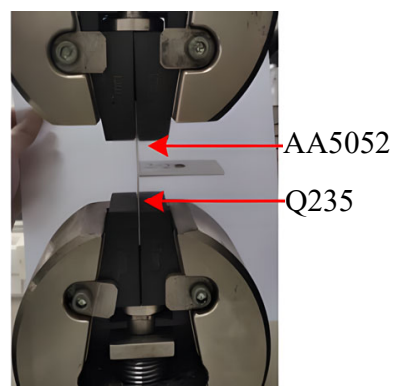

(b)
Fig. 5 Shear and peel experiments. (a) Shear experiment, (b) Peel experiment. 


\section{Results and discussion}

\subsection{Influence law of inclined wall angle of female die}

\section{on clinching joints quality}

According to the analysis of material flow characteristics, the inclined wall structure could effectively improve the clinching quality of heterogeneous sheets. To further study the mechanism of the inclined wall of the female die on the clinching of steel-aluminum heterogeneous sheets, the influence law of the inclined wall on the joint quality was studied by changing the inclined angle of the female die by using the single factor analysis method. Considering that the excessive angle of the inclined wall would lead to dying processing difficulties and reduced die strength, the selection range of the inclined wall angle $\boldsymbol{\alpha}$ was $90^{\circ} \sim 110^{\circ}$.

The change of the inclined wall of the female die would directly affect the plastic rheological behavior of the sheets during clinching. Fig. 6 shows the maximum equivalent plastic strain value in the interlock area of the upper sheet when the inclined wall angle $\boldsymbol{\alpha}$ was $90^{\circ} \sim 110^{\circ}$. From the plastic deformation uniformity of the clinching joints, with the increase of $\boldsymbol{\alpha}$, the strain concentration at the protrusions of the interlock area outer edge of the upper sheet was gradually improved. There was no large strain concentration, and the uniformity of joint deformation was improved. From the maximum equivalent plastic strain of the joints, when $\boldsymbol{\alpha}$ increased, the maximum equivalent plastic strain decreased gradually at the protrusion of the interlock area outer edge of the aluminum sheet. which shows that, as $\boldsymbol{\alpha}$ increased, the trend of sheet metal flowing around the die increased gradually. During clinching, the extrusion force was transmitted by the punch to the upper sheet, and then the upper sheet was plastically deformed so that the force was transmitted to the lower sheet. The aluminum sheet needed high enough strength to transmit the extrusion force, so the aluminum sheet needed large plastic deformation strengthening. Nevertheless, with $\boldsymbol{\alpha}$ increased, the tendency of steel sheets to plastic deformation and the deformation strengthening required by aluminum sheets decreased. It can be seen that the reduction effect of the inclined wall on the maximum equivalent plastic strain of clinching joints was limited.

Then, the mechanism of the inclined wall was discussed from the change of equivalent plastic strain at the protrusion of the interlock area outer edge of the aluminum sheet. As shown in Fig. 6, the influence curve could be divided into three stages: The first stage was the extrusion stage, when $\boldsymbol{\alpha}$ was between $90^{\circ} \sim 96^{\circ}$, as $\boldsymbol{\alpha}$ increased, the maximum equivalent plastic strain decreased linearly from 5.33 MPa to 3.15 MPpa, which decreased by about $41 \%$. In the extrusion stage, as $\boldsymbol{\alpha}$ increased, the sheet metal was easier to squeeze into the die groove to form interlocking, and the deformation resistance of the sheet metal reduced, so the plastic deformation strengthening required for the aluminum sheet was also reduced. The second stage was the radial flow stage, where $\boldsymbol{\alpha}$ was $96^{\circ} \sim 104^{\circ}$. There were two obvious platforms in this stage, but the overall trend of the equivalent plastic strain in this area decreased with the increased of $\boldsymbol{\alpha}$. In addition, to increase the trend of sheet flow to the groove, the inclined wall of the female die also increased the trend of sheet radial flow. As $\boldsymbol{\alpha}$ increased, although the sheet metal squeezed into the die groove began to decrease, the radial resistance of the sheet metal was smaller and easier to flow around. Both effects contributed to further reducing the deformation resistance of the steel sheet. The third stage was the stability stage. As a further increased, the equivalent plastic strain began to increase, but the amount of sheet metal flowing into the die groove remained unchanged. Moreover, the trend of sheet radial flow slows down, the sheet radial flow needed greater plastic deformation. The plastic deformation strengthening required by the aluminum plate increased, so the equivalent plastic strain increased. 


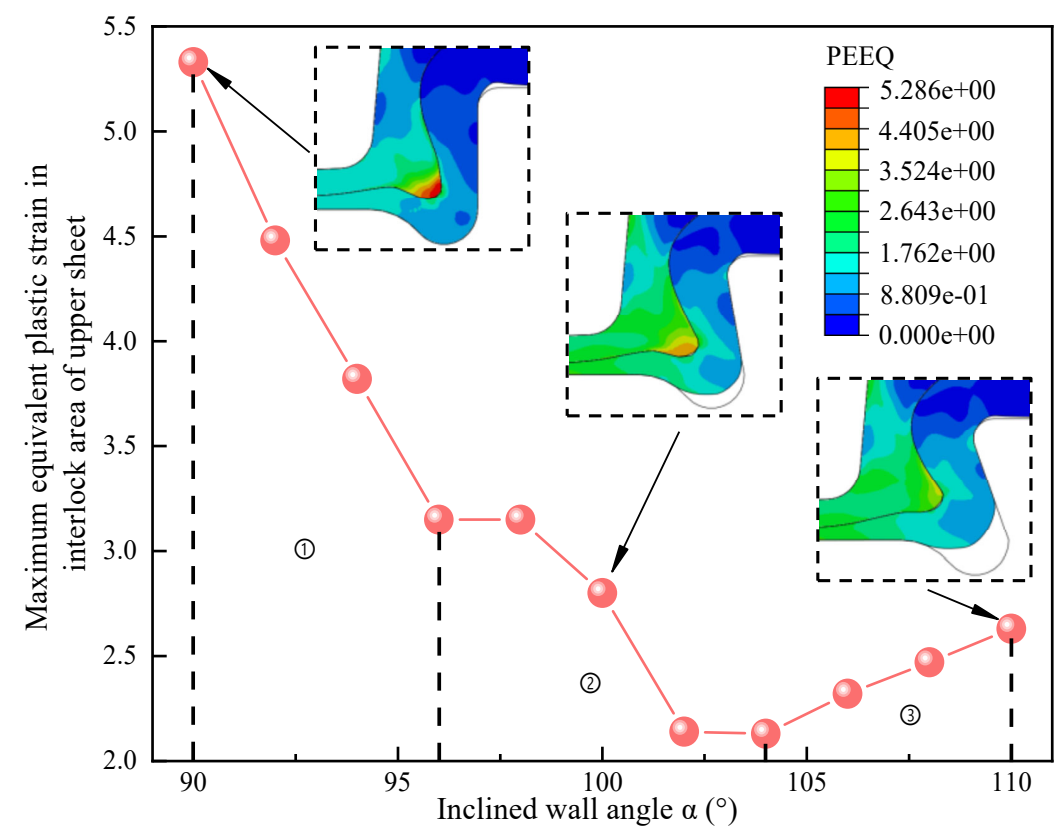

Fig. 6 Effect of inclined wall angle $\alpha$ on maximum equivalent plastic strain in interlock area of upper sheet.

Fig. 7 shows the effect of the inclined wall on the equivalent stress of the clinching joints. Since the Q235 steel sheet with high strength and hardness was used as the lower sheet in the clinching process, the maximum equivalent stress of the clinching joints was also mainly in the area near the concave die groove of the lower sheet. When $\boldsymbol{\alpha}$ was between $90^{\circ} \sim 96^{\circ}$, as $\alpha$ increased, the sheet metal inflow into the groove and the deformation of the steel sheet increased, so the range of large equivalent stress at the bottom of the steel sheet gradually increased. When $\boldsymbol{\alpha}$ was between $96^{\circ} \sim 104^{\circ}$, the radial flow trend increased with the increase of $\boldsymbol{\alpha}$, so the extrusion force of the steel sheet by the inclined wall increased, resulting in the increase of the area of large equivalent stress zone on the sidewall of the clinching joints. When $\boldsymbol{\alpha}$ increased further, the trend of sheet radial flow slow down, and the large equivalent stress region of the steel sheet decreased and remained relatively stable. The variation law of joints equivalent stress with inclined wall further verified the three-stage theory of influence mechanism of the inclined wall structure.
90

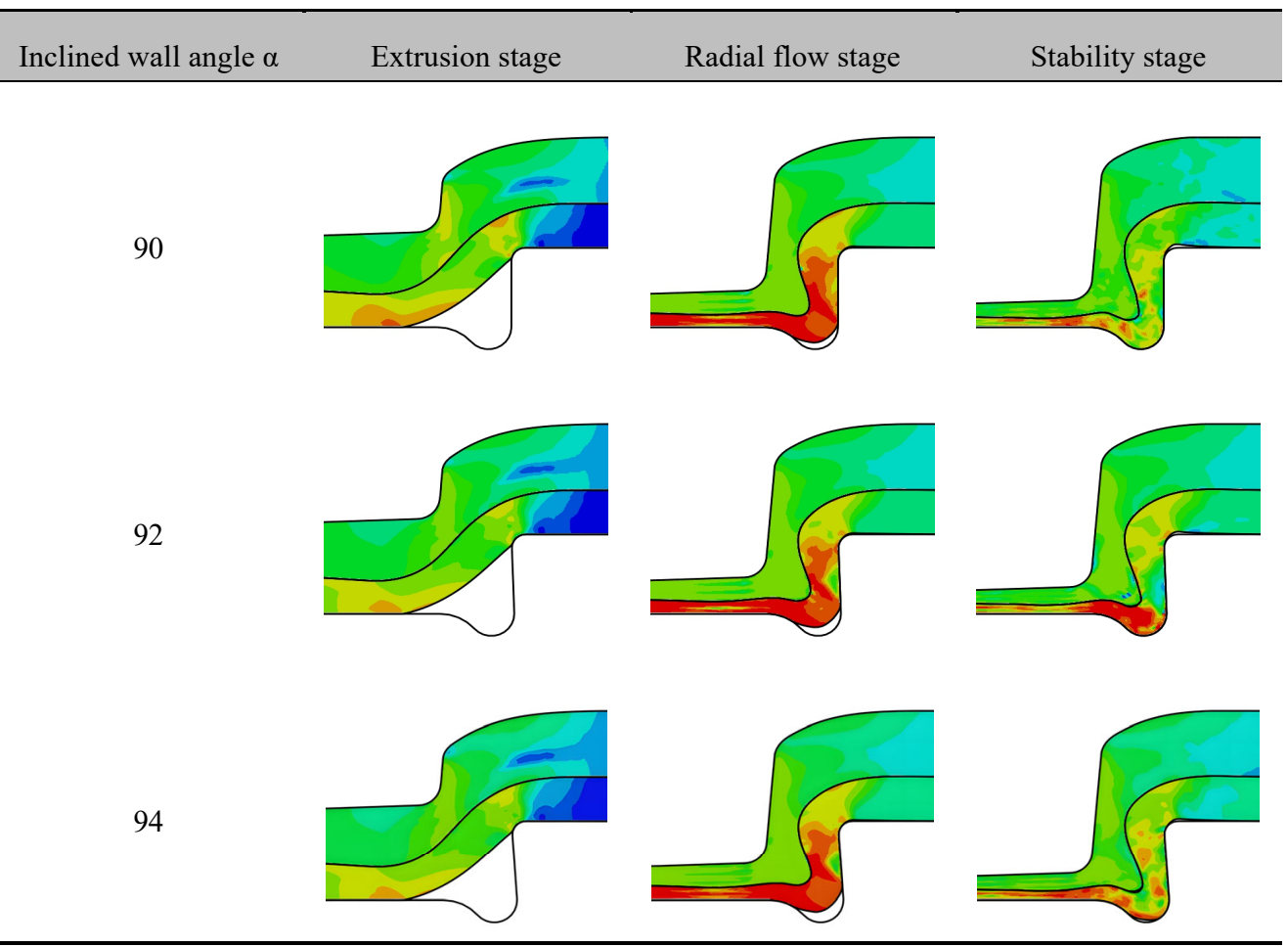




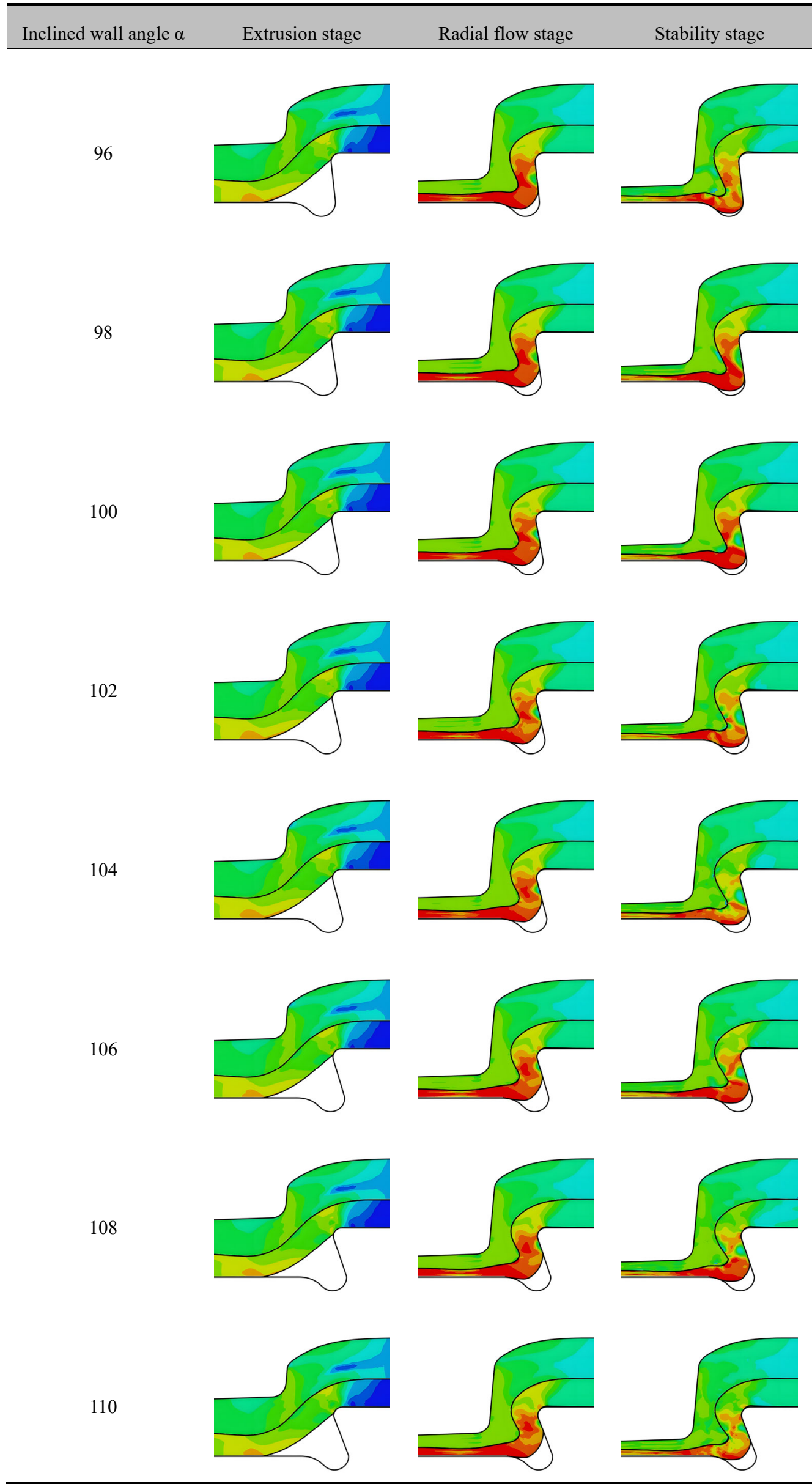

Fig. 7 Effect of inclined wall angle on clinching joints' equivalent stress. 
Fig. 8 shows the relationship between the clinching joints' quality characteristic parameters (neck thickness $T_{n}$ and interlock value $T_{u}$ ) with the inclined wall angle $\boldsymbol{\alpha}$ of the female die. From the previous analysis, it could be seen that the increase of inclined wall angle could increase the trend of sheet flow to groove and radial flow, which was beneficial to increase the interlock value of joints. The effect of inclined wall angle on clinching joints' quality also corresponded to the above three stages: The first stage was the extrusion stage, with inclined wall angle increased, which was beneficial to the extrusion of upper and lower sheets into the die groove. At this time, as $\boldsymbol{\alpha}$ increased, the interlock value of upper and lower sheets also increased, and the increase was greater. The second stage was the radial flow stage, the sheet metal tended to flow radially. As $\boldsymbol{\alpha}$ increased, the interlock value of upper and lower sheets continued to increase, but the increase was less than that in the first stage. The third stage was stability stage, the effect of promoting sheet metal flow to groove and radial flow gradually decreased when inclined wall angle increased, and the increase of interlock value gradually approached zero. Overall, when $\boldsymbol{\alpha}$ increased from $90^{\circ}$ to $100^{\circ}$, the interlock value $T_{u}$ increased from $0.319 \mathrm{~mm}$ to 0.443 $\mathrm{mm}$, an increase of about $38.9 \%$. In the whole process of $\boldsymbol{\alpha}$ increasing, the increase of joints' neck thickness $T_{n}$ was small, only from $0.64 \mathrm{~mm}$ to $0.659 \mathrm{~mm}$.

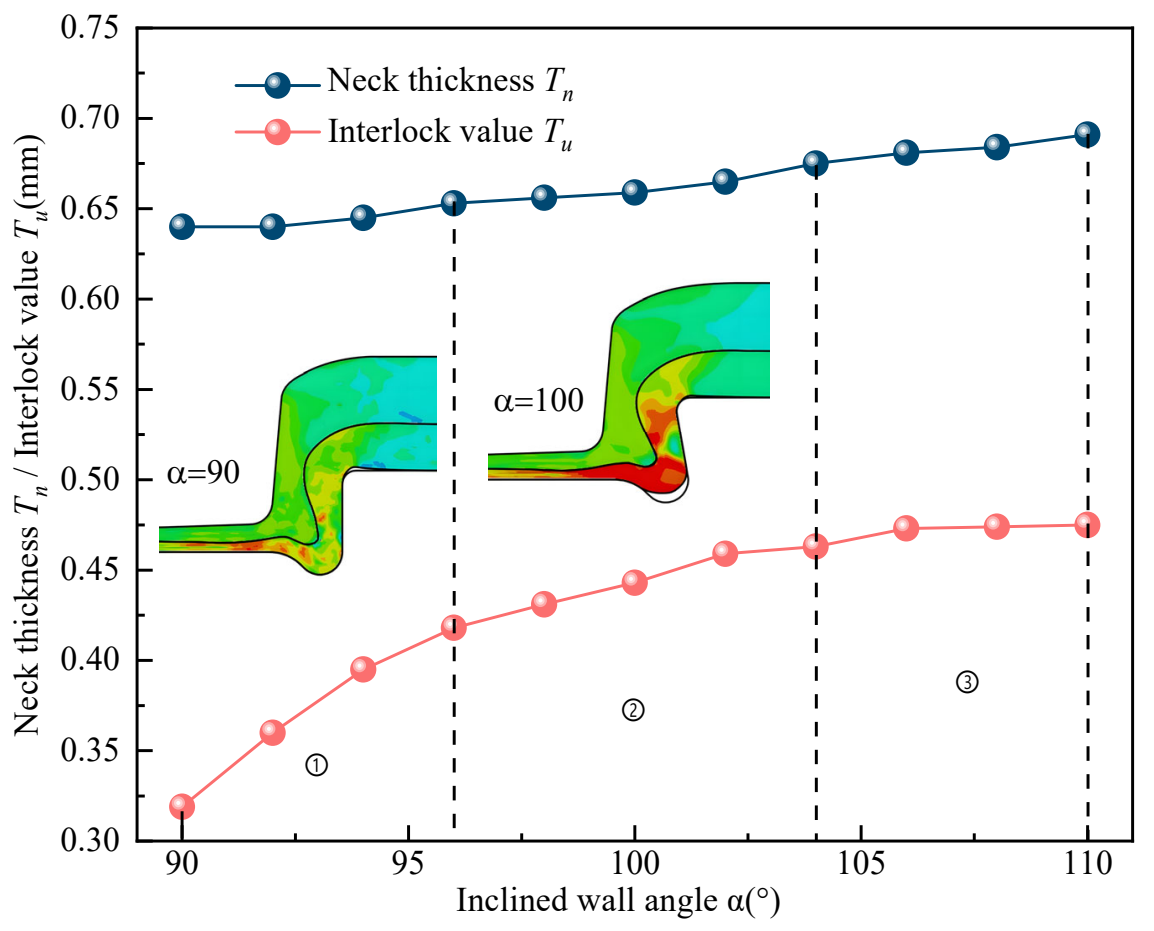

Fig. 8 Effect of inclined wall angle on clinching joints' quality.

\subsection{Results of steel-aluminum clinching joints of the}

\section{inclined wall die}

The appearance of the clinching joints is shown in Fig. 9. It could be seen from Fig. 9 that the protrusion and inclined wall structure at the bottom of the joints were not obvious enough, indicating that there was not enough material for the Q235 steel sheet to squeeze into the groove. This was due to the error in the control of the equipment pressing amount and insufficient punch stiffness, resulting in insufficient pressing of the punch $(<3.8 \mathrm{~mm})$ in the whole clinching process. If the pressing amount was increased to $3.8 \mathrm{~mm}$, it was easy to cause upsetting deformation of the working part of the punch. To protect the die and equipment, the down pressure was still used for plastic clinching. Under the down pressure, the maximum load of the equipment in the clinching process was $47 \mathrm{kN}$.

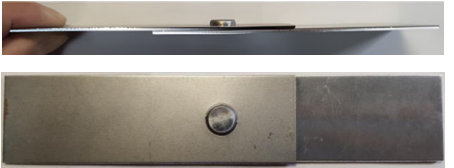

(a)

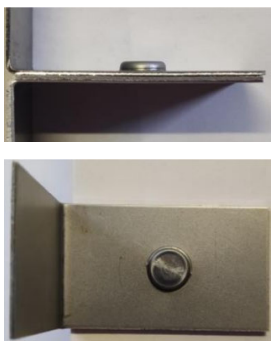

(b)
Fig. 9 The appearance of the steel-aluminum plastic clinching joints of the inclined wall die. (a) Cut and shear samples, (b)

Peel samples.

Fig. 10 shows the comparison between the experimental results and simulation results of the cutting samples of the steel-aluminum plastic clinching joints of the inclined wall die. Although the forming of the steel-aluminum plastic clinching of the 
inclined wall die was not ideal, the experimental results were similar to the simulation results from the geometry of the joint section plane. As could be seen from Fig. 10, the simulation value of neck thickness was highly similar to the experimental value, but there was a large deviation of the interlock value between simulation and experiment. For the reasons of large deviation of the interlock, on the one hand, the die was assumed to be an absolutely rigid body during simulation, and there were some deviations in the material model, which led to a large prediction value of the interlock. On the other hand, after clinching, the aluminum and steel sheets had a certain degree of spring back, which made the experimental value of interlock value too small, as shown in Fig. 10, there was an obvious gap between the two sheets. In addition, the material loss caused by Wire Electrical Discharge Machining also had a certain impact. According to the experimental results, the finite element model of plastic clinching of the inclined wall die was reliable.

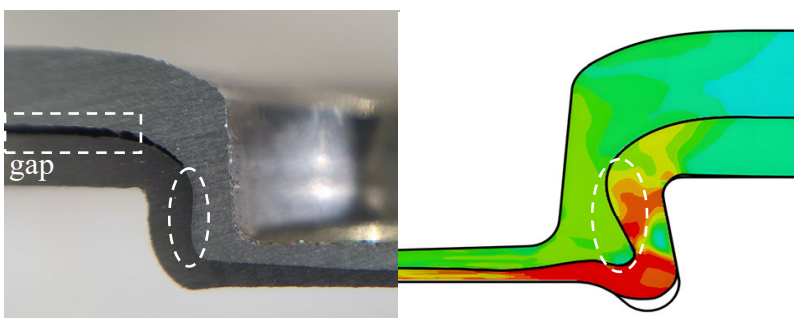

Fig. 10 Comparison between experimental results and simulation results of clinching joints.

Considering the large difference of steel and aluminum properties and the large interlock deviation of steel-aluminum plastic clinching joints of the inclined wall die, Q235 steel sheets were replaced with 5052 aluminum alloy sheets. The aluminum alloy sheets joints are shown in Fig. 11. As could be seen from Fig. 11 (a), after replacing the lower sheet with aluminum sheets with better plasticity, the material was easier to deform and flow, and the bottom protrusion and inclined wall structure of the joints were more obvious, which proved that the inclined wall die was effective. From the joint cross-section in Fig. 11 (b), the neck thickness and interlock value of the joints were relatively large, with the neck thickness of $0.51 \mathrm{~mm}$ and the interlock value of 0.36 $\mathrm{mm}$. Therefore, it could be considered that the inclined wall die was conducive to improving the interlock value of clinching joints.
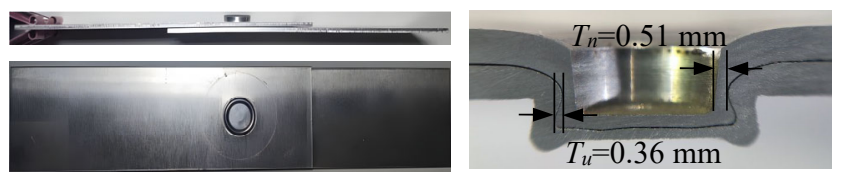

Fig. 11 Aluminum alloy sheets plastic clinching joints of the inclined wall die.

\subsection{Shear and peel experiment results of clinching}

\section{joints}

There are three common failure modes of clinching joints under shear and peel load: neck fracture, upper sheet separation, and mixed failure of fracture and separation. The Shear and peel failure modes of clinching joints samples were shown in Fig. 12. As shown in Fig. 12 (a) and (b), the main failure mode of the joints sample under shear and peel load was the separation failure of the upper sheet.

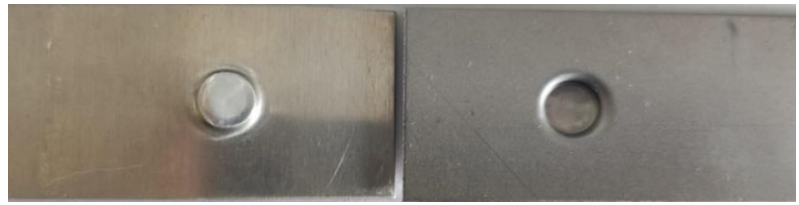

(a)

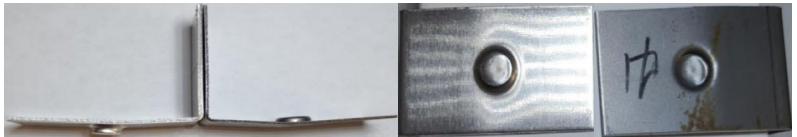

(b)

Fig. 12 failure modes of clinching joints samples. (a)Shear failure, (b)Peel failure.

The load-displacement curve corresponding to clinching joints failure is shown in Fig. 13. The maximum shear strength of the clinching joints was $2170 \mathrm{~N}$ and the maximum peel strength was $269.5 \mathrm{~N}$. It could be seen from the sheer load-displacement curve of the joints that the shear failure of the joints could be divided into four stages: The first stage was the initial stage of joints loading. Eliminated the gap between the fixture and the test piece. At this time, the joint load had no obvious change. The second stage was the elastic deformation stage of the sheets. At this time, the curve was almost an oblique line, and the load rose to about $700 \mathrm{~N}$. The third stage was the plastic deformation stage of the upper aluminum sheet. With the progress of shear, the sheet displacement increased, and the aluminum sheet had obvious plastic deformation. At the same time, the joints had the trend to separate. When the maximum load value was separated, the joint partially fell out and the load began to drop. The fourth stage was the joint failure stage. At this time, there was still part of the upper sheet that did not separate. With the shear continuing, this part would undergo plastic deformation and the joints would fail. When the joints are completely separated, the load would drop to 0 . From the analysis of the load-displacement curve of the joints peeling, the peel failure process was different from the shear failure, and its elastic deformation stage was very short, which could be ignored. In the process of joint failure, it was mainly the plastic deformation of the upper and lower sheets. At the same time, the lower steel sheet was mainly displaced under the clamp, so the deformation 
degree of the steel sheet was greater. At last, when the load reached the maximum value, the clinching joints would separate and fail, and the load would drop to 0 .
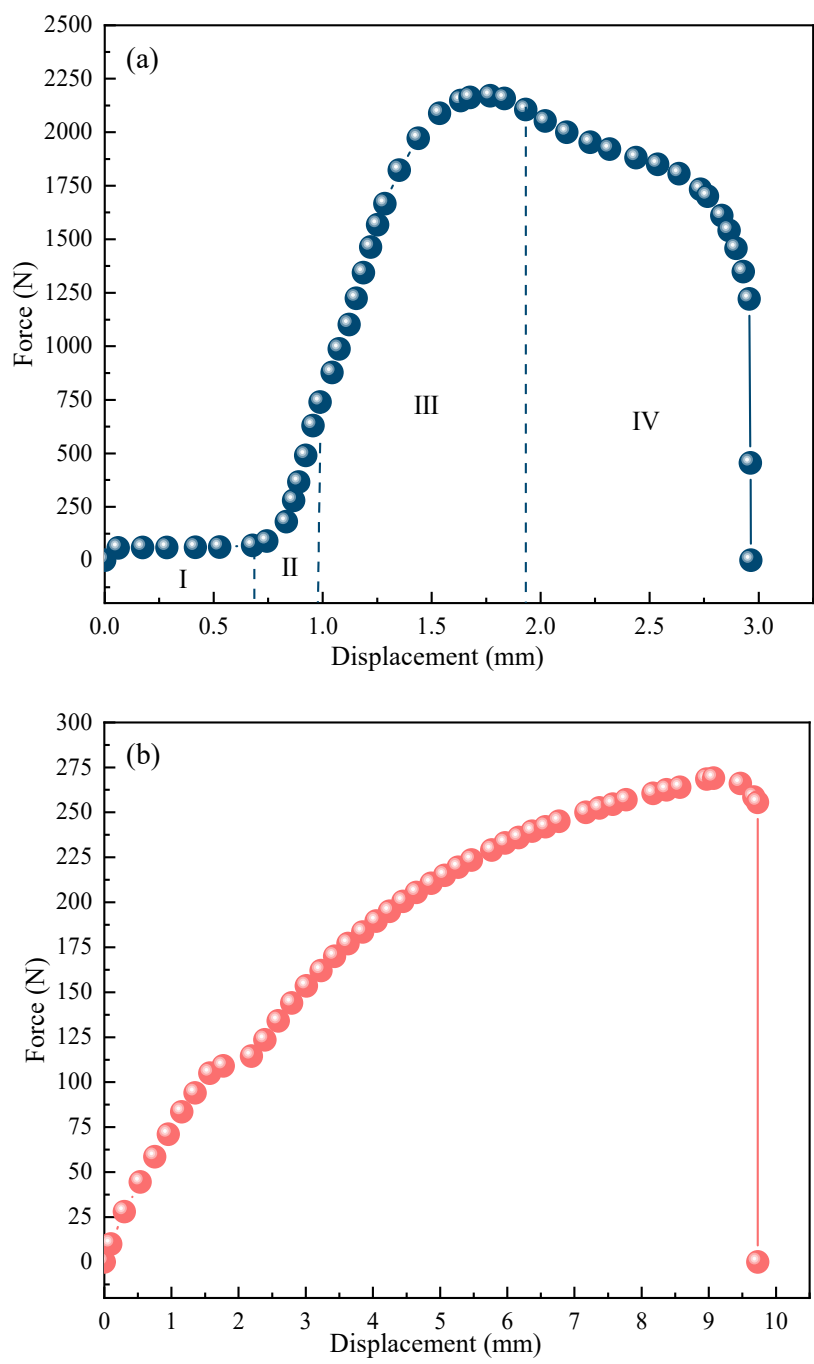

Fig. 13 Load-displacement curve. (a) Load-displacement curve under shear condition, (b) Load-displacement curve under peel condition.

\section{Conclusion}

In this work, Q235 steel and 5052 aluminum alloy sheets were taken as the research object, according to the deformation and flow characteristics of sheets in clinching, the inclined wall dies for plastic clinching were improved. The clinching process of the inclined wall die was analyzed by elastic-plastic finite element simulation and experimental research, and the failure mode and mechanism of the clinching joints under shear and peel load were deeply analyzed. The main conclusions were as follows:

(1) The improved inclined wall die can effectively increase the interlock value of plastic clinching joints of steel-aluminum heterogeneous sheets and reduce the maximum joining force during clinching. When the inclined wall angle $\boldsymbol{\alpha}$ increases from $90^{\circ}$ to $100^{\circ}$, the interlock value increases by $38.9 \%$, and the maximum joining force decreases by $8.3 \%$.

(2) The action mechanism of the inclined wall die was explored through the finite element method. The effect of inclined wall structure on joint quality can be divided into extrusion stage, radial inflow stage, and stability stage.

(3) The feasibility of practical application of inclined wall die was verified by experiments. Comparing the experimental results with the simulation results, it is found that they are in a high degree of agreement, which proves that the plastic clinching finite element model of the inclined wall die has high reliability.

(4) Finally, the failure mode and mechanism of the clinching joints were investigated by shear and peel experiments. The main failure mode of clinching joints of the inclined wall die is separation failure.

Author contribution Menghan Wang conceived and designed the experiments; Yifeng Chen and Yan Han performed the experiments; Lei Li and Menglong Du analyzed the data; Yifeng Chen and Yan Han wrote the paper.

Funding This research work is supported by the Project of International Scientific and Technological Innovation Cooperation (Grant No. 2021YFH0031)

Availability of data and material Not applicable

\section{Declarations}

Competing Interests The authors declare no competing interests.

Consent to participate All authors agreed with the consent to participate.

Consent for publication All authors have read and agreed to the published version of the manuscript.

\section{References}

[1] Anil KD, Waleed A, Indira B (2021) Mechanical characterization of AA5083 aluminum alloy welded using resistance spot welding for the lightweight automobile body fabrication. Materials Today: Proceedings 45:5139-5148.https://doi.org/10.1016/j.matpr.2021.01.64 6

[2] Chu YT, Sun LY, Li LJ (2019) Lightweight scheme selection for automotive safety structures using a quantifiable multi-objective approach. Journal of Cleaner Production 
241:118316.https://doi.org/10.1016/j.jclepro.2019.118316

[3] Juergen H (2011) Aluminium in Innovative Light-Weight Car Design. Materials Transactions 52(5): 818-824. https://doi.org/10.2320/matertrans.L-MZ201132

[4] Li H, Yan ZH, Cao LY (2018) Bake hardening behavior and precipitation kinetic of a novel $\mathrm{Al}-\mathrm{Mg}-\mathrm{Si}-\mathrm{Cu}$ aluminum alloy for lightweight automotive body. Materials Science and Engineering: A 728:88-94. https://doi.org/10.1016/j.msea.2018.05.014

[5] Lambiase F, Di Ilio A (2014) An experimental study on clinched joints realized with different dies. Thin-Walled Structures 85: 71-80. https://doi.org/10.1016/j.tws.2014. 08.004

[6] Lambiase F, Ko DC (2017) Two-steps clinching of aluminum and carbon fiber reinforced polymer sheets. Compos Struct 164:180-188

[7] Chen C, Zhao SD, Cui MC, Han XL, Zhao XZ, Fan SQ (2017) Study on the flat-reshaping technology with no rivet for joining aluminium alloy sheet of the automobile. Journal of Mechanical Engineering 53(18): 42-48. doi:10.3901/JME.2017.18.042

[8] Chen C, Zhao SD, Cui MC, Han XL, Ning YB (2016) Numerical and experimental investigations of the reshaped joints with and without a rivet. International Journal of Advanced Manufacturing Technology 88:2039-2051.http://doi.org/ 10.1007/s00170-016-8889-5

[9] Chen C, Ouyang YW, Qin DL (2021) Finite element analysis of material flow in flat-rivet clinching process. International Journal of Advanced Manufacturing Technology 116:1961-1974. http://doi.org/10.1007/s001 70-021-07532-2

[10] Lee CJ, Lee JM, Ryu HY, Lee KH, Kim BM, Ko DC (2014) Design of hole-clinching process for joining of dissimilar materials-Al6061-T4 alloy with DP780 steel, hot-pressed 22MnB5 steel, and carbon fiber reinforced plastic. J Mater Process Technol 214:2169-2178. https://doi.org/10.1016/ j.jmatprotec.2014.03.032

[11] Lee CJ, Kim BM, Kang BS, Song WJ, Ko DC (2017) Improvement of joinability in a hole clinching process with aluminum alloy and carbon fiber reinforced plastic using a spring die. Composite Structures 173:58-69. https://doi.org/10.1016/j.compstruct.2017.04.010

[12] Lin PC, Lin JW, Li GX (2018) Clinching process for aluminum alloy and carbon fiber-reinforced thermoplastic sheets. The International Journal of Advanced Manufacturing Technology 97:529-541. https://doi.org/10.1007/ s00170-018-1960-7

[13] He XC, Liu FL, Xing BY, Yang HY, Wang YQ, Gu FS, Andrew B, (2014) Numerical and experimental investigations of extensible die clinching. The International Journal of Advanced Manufacturing Technology 74:1229-1236. doi: 10.1007/s00170-0146078-y
[14] Zhang Y, He S, Yang L, Guo J, Luo Z, Cheng YM (2017) Joining aluminum alloy 5052 sheets via novel hybrid resistance spot clinching process. Materials \& Design 118: 36-43. https://doi.org/10.1016/j.matdes.2017.01.017

[15] Stephan B, Merklein M, Karl R, Michael R, Michael Z (2010) Development of a mechanical joining process for automotive body-in-white production. International Journal of Material Forming, 2010, 3(1): 1059-1062. http://doi.org/10.1007/s12289-010-0953-3

[16] Eshtayeh M, Hrairi M, Mohiuddin AKM (2016) Multi objective optimization of clinching joints quality using Grey-based Taguchi method. International Journal of Advanced Manufacturing Technology 87:233-249. doi:10.1007/s00170-016-8471-1

[17] Varis JP (2002) The suitability of round clinching tools for high strength structural steel. Thin-Walled Structures 40: 225-238. https://doi.org/10.1016/S0263-8231(01)00063-5

[18] Varis JP (2003) The suitability of clinching as a joining method for high-strength structural steel. Journal of Materials Processing Technology 132(1-3): 242-249. https://doi.org/10.1016/S0924-0136(02)00933-0

[19] Lei L, He XC, Zhao DS, Zhang Y, Gu FS, Andrew B (2018) Clinch-bonded hybrid joining for similar and dissimilar copper alloy, aluminium alloy and galvanised steel sheets. Thin-Walled Structures 131:393-403. https://doi.org/10.1016/j.tws.2018.07.017

[20] Song YL, Yang LL, Zhu GP, Hua L, Liu GZ (2019) Numerical and experimental study on failure behavior of steel-aluminium mechanical clinched joints under multiple test conditions. International Journal of Lightweight Materials and Manufacture 2:72-79. https://doi.org/10.1016/j.ijlmm.2018.12.005

[21] Calabrese L, Galtieri G, Borsellino C, Di Bella G, Proverbio E (2016) Durability of hybrid clinch-bonded steel/aluminum joints in salt spray environment. The International Journal of Advanced Manufacturing Technology 87:3137-3147. http://doi.org/10.1007/s001 70-016-8701-6

[22] Zhao L, He XC, Xing BY, Gu FS, Andrew B (2015) Influence of sheet thickness on fatigue behavior and fretting of self-piercing riveted joints in aluminum alloy 5052. Materials and Design 87:1010-1017. https://doi.org/10.1016/j.matdes.2015.08.121

[23] Lin PC, Fang JC, Lin JW, Tran XV, Ching YC (2020) Preheated (Heat-Assisted) Clinching Process for Al/CFRP Cross-Tension Specimens. Materials 13,4170. https://doi.org/10.3390/ma13184170

[24] Chen YW, Li MJ, Yang XJ, Wei K (2020) Durability and mechanical behavior of CFRP/Al structural joints in accelerated cyclic corrosion environments. International Journal of Adhesion and Adhesives 102,102695. https://doi.org/10.1016/j.ijadhadh.2020.102695 


\section{Supplementary Files}

This is a list of supplementary files associated with this preprint. Click to download.

- SupplementaryMaterial.docx 